\title{
Method for identifying the phosphorylation site of Maize Starch Synthase I
}

\author{
Clare Barker, Nadya Romanova, Michael J. Emes and Ian J. Tetlow
}

This manuscript was prepared under the supervision of Professor Ian J. Tetlow, Department of Molecular and Cellular Biology, College of Biological Sciences.

\begin{abstract}
Multiple forms of starch synthases (EC 2.4.1.21) are critical for the synthesis of starch in higher plants. These enzymes catalyze the extension of linear glucan chains by the transfer of glucose from the nucleotide sugar ADPglucose. Recombinant maize starch synthase I (rSSI) was purified from Escherichia coli in order to study the regulation of this enzyme by protein phosphorylation. The rSSI was phosphorylated in vitro by incubation with $\left[\gamma_{-}{ }^{32} \mathrm{P}\right]-\mathrm{ATP}$ and maize amyloplast lysates, which were used as a source of protein kinase. Maximal phosphorylation of rSSI was achieved within 20 minutes, and there was no noticeable change in the amount of phosphorylation beyond this time. Phosphoamino acid analysis of rSSI indicated phosphorylation of one or more serine residues. In order to purify and identify the phosphopeptides, phosphorylated rSSI was digested with trypsin to yield smaller peptides, which were then concentrated using Immobilized Metal Affinity Chromatography (IMAC). Potential phosphopeptides eluting from the IMAC column were purified and putatively identified using reversed-phase (C18 column) High Pressure Liquid Chromatography (HPLC). They were then analyzed by mass spectrometry using Matrix-Assisted Laser Desorption/Ionization-Time of Flight (MALDI-TOF) which yielded the mass of potential phosphopeptides.
\end{abstract}

$\mathrm{S}$ tarch is a glucose polymer synthesized in plastids of higher plants and functions as a major energy storage molecule. Transient starch is synthesized by chloroplasts in the leaves of plants during the day, and it is degraded overnight to fuel non-photosynthetic metabolic pathways. ${ }^{15}$ Within storage tissues and developing seeds of higher plants, starch for long-term storage is synthesized by nonphotosynthetic plastids called amyloplasts. ${ }^{15}$ Two types of glucose polymers can be present within the starch granule: amylose and amylopectin. Amylose consists primarily of unbranched glucose chains with $\alpha-(1 \rightarrow 4)$ linkages, which are generally believed to exist as single helices or random coils within the amylopectin matrix. ${ }^{14}$ Amylopectin on the other hand, represents approximately $75 \%$ of the starch granule by mass,${ }^{14}$ and is a large glucose polymer with regular branch points formed by $\alpha-(1 \rightarrow 6)$ linkages, which attach unbranched $\alpha-(1 \rightarrow 4)$ glucan chains to the main body of the amylopectin. ${ }^{9}$ The organization of amylose and amylopectin within the starch granule allows for dense and efficient packaging of starch into an insoluble body within the plastid. The synthesis of the starch granule occurs by the complex and coordinated action of a variety of enzymes. Starch synthases (SSs, 2.4.1.21) are a class of enzymes which elongate linear $\alpha-(1 \rightarrow 4)$ linked glucose chains by catalyzing the transfer of the glucose portion of adenosine 5, diphosphate glucose (ADPGlc) to the reducing end of an existing glucan chain. ${ }^{15}$ SSI is a soluble enzyme distributed

between the starch granule and the stroma. ${ }^{1}$ SSI functions to add glucose units to the reducing end of existing $\alpha-(1 \rightarrow 4)$ linked glucan chains of amylopectin if they have a degree of polymerization (DP) of less than 10 glucose units. ${ }^{2}$ As the chains grow longer than a DP of approximately 20 glucose units, SSI will no longer add glucose and other enzymes will continue the synthesis of amylopectin. ${ }^{2}$ These enzymes include starch synthases II and III, which catalyze the extension of progressively longer glucan chains and starch branching enzymes (SBEs, EC 2.4.1.18) which produce the $\alpha-(1 \rightarrow 6)$ linkages in amylopectin. ${ }^{14} \mathrm{SS}$ IV is known to exist in leaves and non-photosynthetic tissues, and although the precise function of SSIV remains unknown, recent evidence suggests it is involved in starch granule initiation. ${ }^{12}$ Debranching enzymes (DBEs, EC 3.2.1.41 and EC 3.2.1.68) also play a role in amylopectin synthesis; they hydrolyze $\alpha$ $(1 \rightarrow 6)$ linkages of amylopectin and are necessary for the proper formation of crystalline amylopectin. ${ }^{10}$ Granule bound (GB) forms of starch also synthases exist: GBSSI and GBSSII are found within the amylopectin matrix and function to elongate amylose. ${ }^{14}$

Little is known of the post-translational regulation of starch biosynthetic enzymes. Recent work suggests the involvement of protein-protein interactions, some of which have been shown to be dependant on the phosphorylation state of the enzymes involved. ${ }^{13,}{ }^{16}$ Complexes containing SSI, SSIIa and either SBEIIa or SBEIIb have been shown to 
exist in wheat amyloplasts. ${ }^{13}$ The phosphorylation state of maize SSI may play a role in regulating enzymatic activity and protein-protein interactions. The focus of the research outlined in this paper was to investigate the phosphorylation site of maize SSI.

Protein phosphoryation is currently a major area of interest because it plays a significant role in the regulation of enzymatic activity; as such, many methods for studying phosphorylated proteins have been developed. Phosphoamino acid analysis, as described by van der Greer et al., is a proven technique for identifying the presence of one or more phosphoamino acids, such as phosphoserine, phosphothreonine and/or phosphotyrosine. ${ }^{18}$ Once the type(s) of phosphoamino acids that are present within the protein is/are known, the specific phosphorylation site of a protein can be identified. Mitchelhill and Kemp describe a method whereby the protein is digested by trypsin, and the peptides are separated by reversed-phase High Pressure Liquid Chromatography (HPLC) then analyzed by mass spectrometry using Matrix-Assisted Laser Desorption/ Ionization-Time of Flight (MALDI-TOF). ${ }^{8}$ The use of Immobilized Metal Affinity Chromatography (IMAC) has previously been shown to enrich phosphopeptides which can then be analyzed through the use of other methods. IMAC enriches phosphopeptides in a solution by selectively binding the negative phosphate group of a phosphopeptide to positively charged $\mathrm{Fe}(\mathrm{III})$ bound to a resin in a column. The phosphopeptides can be eluted by a solution of phosphate salt. For an overview and protocols for IMAC, refer to Turkina and Vener. ${ }^{17}$

\section{Materials ANd MethodS}

\section{Maize Plants and Preparation of Amyloplast Lysates}

Maize (Zea mays L.) was grown in the field by the University of Guelph during the summer of 2008. Ears were harvested approximately 16 days after pollination (DAP) and amyloplasts were extracted the same day as the harvest. Maize amyloplast extracts were prepared from endosperm tissue as described by Hennen-Bierwagen et al. ${ }^{5}$ which is a modified version of the procedure for wheat described by Tetlow et al. ${ }^{16}$ The endosperm was minced in a Petri dish on ice using a razor blade while suspended in amyloplast extraction buffer (50mM $N$-(2-hydroxyethyl) piperazine- $N$ 'ethanesulfonic acid (HEPES)/KOH, pH 7.5, 0.8M sorbitol, $1 \mathrm{mM} \mathrm{KCl}, 2 \mathrm{mM} \mathrm{MgCl}_{2}$, and $1 \mathrm{mM} \mathrm{Na} \mathrm{Na}_{2}$-EDTA). This mixture, containing amyloplasts and starch granules, was filtered, and then layered over 3\% (w/v) Histodenz (Sigma, catalog no. D2158), and amyloplast extraction buffer. This solution was centrifuged at $100 \mathrm{~g}$ and the supernatant containing starch and whole amyloplasts was collected. The amyloplasts were lysed using rupturing buffer $(100 \mathrm{mM} \mathrm{N}$ tris (hydroxymethyl) methyl glycine (Tricine)/KOH, $\mathrm{pH} 7.8$, $1 \mathrm{mM} \mathrm{Na}_{2}$-EDTA, $1 \mathrm{mM}$ dithiothreitol (DTT), $5 \mathrm{mM} \mathrm{MgCl}$, and a protease inhibitor cocktail from Sigma-Aldrich, catalog no. P 9599, used at $10 \mu \mathrm{L}$ per $\mathrm{cm}^{3}$ ). The lysed amyloplasts solution was centrifuged at $13500 \mathrm{~g}$ at $4^{\circ} \mathrm{C}$ to remove starch granules. The supernatant was collected, and was ultracentrifuged at $150000 \mathrm{~g}$ to remove the remaining plastidial membranes.

\section{Expression of Recombinant Maize SSI}

SSI plasmid vectors (pET 29a, Novagen) were provided to Ian J. Tetlow's lab by Dr. A. Myers and Dr. M. James from Iowa State University. The plasmid contained amino acids 39 to 640 of SSI since amino acid 39 has been identified as the mature N-terminus of the protein, ${ }^{6}$ and an S-tag was fused to the N-terminus of the amino acid sequence. The rSSI was expressed in the BL21-CodonPlus (DE3)-RP strain of Escherichia coli and rSSI was isolated according to the Novagen manual for BugBuster Protein Extraction Reagent (protocol TB245 Rev. E 0304). The rSSI was purified and refolded according to the Novagen manual for Protein Refolding. Modifications to this protocol were as follows: the first dialysis buffer included $1 \mathrm{mM}$ ditrithreitol (DTT) and $1 \mathrm{mg} / \mathrm{mL}$ maltoheptaose, the second included $1 \mathrm{mM}$ DTT, and the third and fourth both included $0.1 \mathrm{mM}$ DTT.

\section{Polyclonal Maize SSI Antibodies}

The polyclonal maize SSI antibodies were produced as described in Liu et al. ${ }^{7}$ Rabbits were injected with the commercially prepared amino acid sequence AEPTGEPASTPPPVPD ${ }^{\mathrm{AA}}$ which corresponds to residues 72 to 87 of SSI. Antibodies were purified from the crude rabbit antiserum using peptide affinity columns, composed of the abovementioned SSI amino acid sequence linked with sulfolink resin slurry. The column was washed (Tris- $\mathrm{HCl} \mathrm{pH}$ 8.5 ), then blocked with $50 \mathrm{mM}$ cysteine in wash buffer. Rabbit antiserum was applied to the column to allow for antibody binding to the SSI peptide. Antibodies remained bound to the column while all other components of the antisera were washed out using three buffers: RIPA buffer [50mM Tris-HCl, pH 7.5, $150 \mathrm{mM} \mathrm{NaCl}, 1 \%$ (w/v) nonyl phenoxylpolyethoxyl ethanol (NP-40), $0.5 \%$ (w/v) Nadeoxycholate, $0.1 \%$ (w/v) sodium dodecyl sulphate (SDS)], sarcosyl buffer (NETN (20mM Tris-HCl, pH 8.0, $1 \mathrm{M} \mathrm{NaCl}$, $1 \mathrm{mM} \mathrm{Na}$-EDTA and $\left.^{2} .5 \%(\mathrm{w} / \mathrm{v}) \mathrm{NP}-40\right)$ ) and $10 \mathrm{mM}$ Tris$\mathrm{HCl} \mathrm{pH} 7.8$ buffer. The antibodies that remained bound to the column were eluted using $100 \mathrm{mM}$ glycine $\mathrm{pH} 2.5$. 


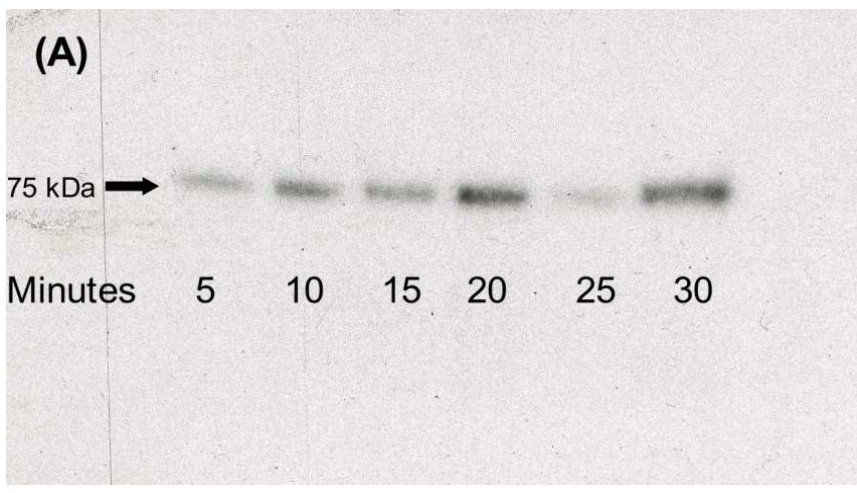

Figure 1: Autoradiographs showing the phosphorylation of rSSI with incubation times of 5 to 30 minutes, and 30 to 180 minutes.

Fourty-two micrograms of rSSI was immobilized on S-protein agarose and phosphorylated by incubation with amyloplast lysates as a source of kinase and $0.1 \mathrm{mM}\left[\gamma-{ }^{32} \mathrm{P}\right]-\mathrm{ATP}$. At the specified times, $100 \mu \mathrm{L}$ of the solution was removed, which contained $7 \mu \mathrm{g}$ of $\mathrm{rSSI}$, and the phosphorylation reaction was terminated by washing the S-protain agarose (bound to rSSI). The presence of rSSI was tested for and confirmed by immunoblotting of the autoradiographed nitrocellulose membrane. The result shown for 25 minutes should be discounted as some S-protein agarose was lost during the washing phase.

\section{SDS-PAGE and Immunoblotting}

SDS-PAGE and immunoblotting were performed based on the method outlined in Tetlow et al. ${ }^{13}$ Samples were prepared by boiling for 5 minutes in SDS loading buffer. The SDS gels used were $4-16 \%$ gradient gels prepared using a BioRad Model 485 Gradient Former. Gels were either stained by a colloidal Coomassie G-250 kit (Simply Blue Safestain, Invitrogen) or silver stained by the method described by Shevchenko et $\mathrm{al},{ }^{11}$ and were run at room temperature in a MOPS running buffer. For immunoblotting, proteins were transferred to nitrocellulose membranes, then blocked with bovine serum albumin (BSA), and exposed to antibodies as described by Harlow and Lane. ${ }^{4}$

\section{SS Zymogram}

Zymograms to test rSSI activity were carried out as described by Liu et al. ${ }^{7}$ which were based on methods previously described by Tetlow et al. ${ }^{13}$ The zymograms were native $5 \%(\mathrm{w} / \mathrm{v})$ polyacrylamide gel assays, that included $10 \mathrm{mg}$ of the $\alpha$-amylase inhibitor Acarbose ("Prandase", Bayer), and $0.3 \%(\mathrm{w} / \mathrm{v})$ rabbit liver glycogen (type III, Sigma-Aldrich) which acted as a glucan chain primer. Recombinant SSI was incubated in the gel for 48 to 72 hours in buffer (50mM glycylglycine, $\mathrm{pH} 9.0,100 \mathrm{mM}\left(\mathrm{NH}_{4}\right)_{2} \mathrm{SO}_{4}$, $20 \mathrm{mM}$ DTT, $5 \mathrm{mM} \mathrm{MgCl}_{2}, 0.5 \mathrm{mg} / \mathrm{ml}$ BSA, $4 \mathrm{mM}$ ADPGlc). Zymograms were developed in Lugol's solution and immediately analyzed.

\section{In vitro Phosphorylation of Recombinant Maize SSI and Immobilized S-tagged rSSI Pull-Down}

The method for in vitro phosphorylation of amyloplast proteins is described by Liu et al. ${ }^{7}$ Plastid lysates were used as a source of kinase and were incubated with gentle rocking for 20 minutes with rSSI (protein ratio of $8: 1$ ) and $0.1 \mathrm{mM}$ ATP (either $250 \mu \mathrm{Ci}\left[\gamma_{-}{ }^{32} \mathrm{P}\right]-\mathrm{ATP}$ (Perkin-Elmer) or nonradioactive ATP as the experiment required). S-protein agarose was blocked by incubating it at room temperature with $1.5 \%$ BSA and was then added to the rSSI solution in a ratio of 1:1 rSSI to S-protein agarose by mass (to reduce nonspecific binding). Incubation continued for an additional 30 minutes. The reaction was terminated by washing the $\mathrm{S}$ protein Agarose beads with wash buffer $(20 \mathrm{mM}$ Tris- $\mathrm{HCl} \mathrm{pH}$ $7.5,750 \mathrm{mM} \mathrm{NaCl}, 5 \mathrm{mM}$ DTT, $0.1 \%$ Triton X-100). The Sprotein agarose beads and attached proteins were collected by low speed centrifugation.

\section{Phosphoamino Acid Analysis}

${ }^{32} \mathrm{P}$-labelled rSSI was run on SDS-PAGE, and then excised from the gel for partial acid hydrolysis, as described by Tetlow et al. ${ }^{16}$ and van der Greer. ${ }^{18}$ The gel slices were incubated at $110^{\circ} \mathrm{C}$ for 1 hour in a $5.7 \mathrm{M} \mathrm{HCl}$ solution. Phosphoamino acid standards (Sigma-Aldrich) and rSSI samples were determined by autoradiography.

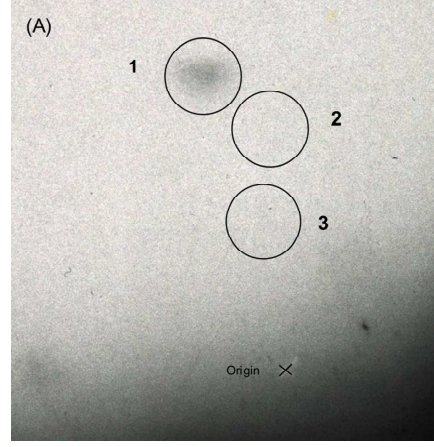

(B)

Figure 2: Autoradiograph of the 2D thin layer chromatography separation of phosphoamino acids (A) and corresponding phosphoamino acid standards (B).

Recombinant SSI was phosphorylated with $\left[\gamma-{ }^{32} \mathrm{P}\right]$-ATP and maize amyloplast lysates, which were used as a source of protein kinase. Recombinant SSI was immobilized on S-protein agarose and subjected to partial acid hydrolysis in 5.7M HCL at $110^{\circ} \mathrm{C}$. The resulting amino acids were resolved using $2 \mathrm{D}$ thin layer chromatography. The marked zones in both images correspond to the phosphoamino acid standards: 1, phosphoserine; 2 , phosphothreonine; 3 , phosphotyrosine. The autoradiograph (A) indicates ${ }^{32} \mathrm{P}$-labeled amino acids were present at the position of phosphoserine. The thin layer chromatography plate (B) shows $1 \mu \mathrm{g}$ of each phosphoamino acid standard visualized by $0.25 \%$ Ninhydrin in acetone. 


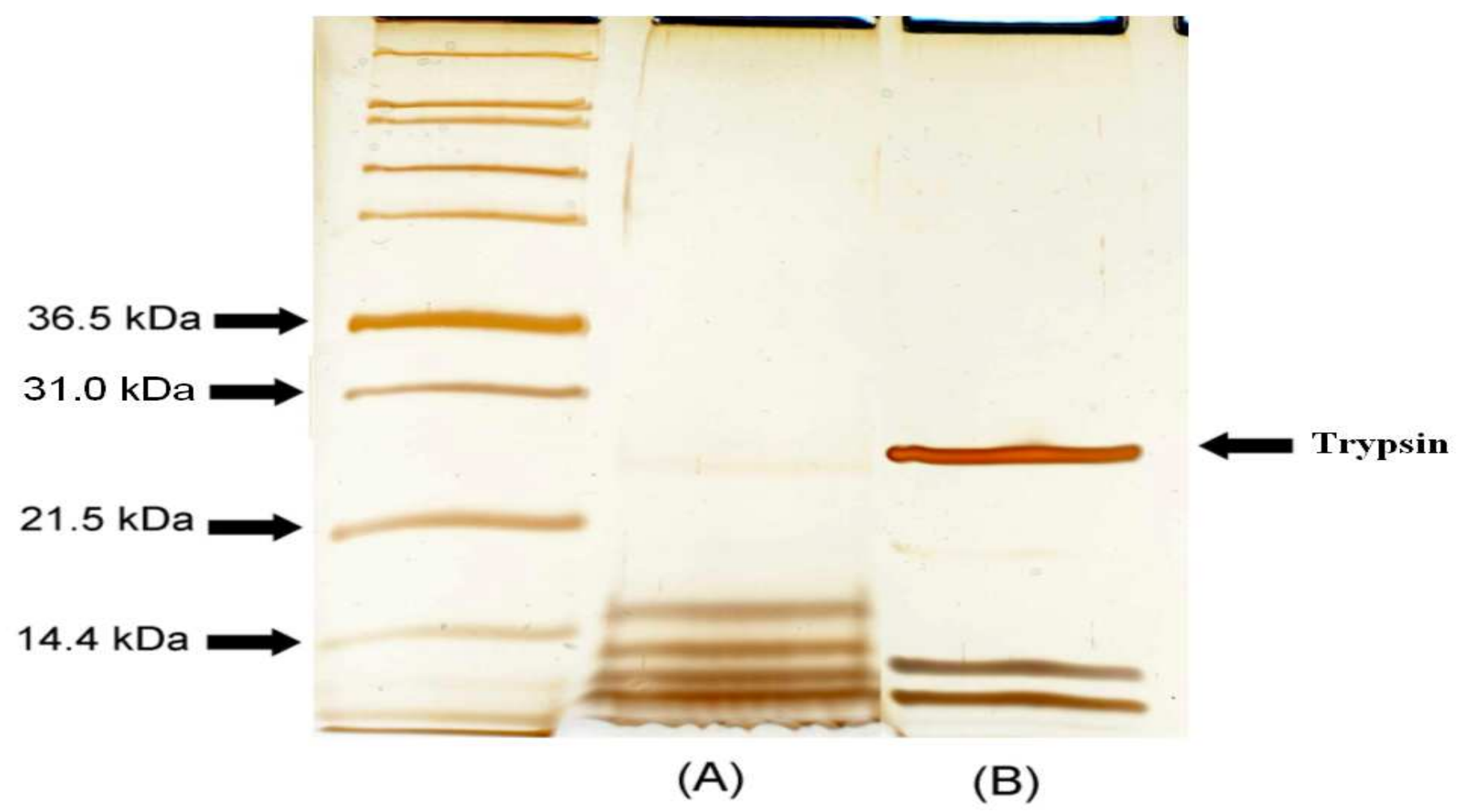

Figure 3: SDS-PAGE of a trypsin digestion of rSSI and a control solution containing fresh trypsin.

Recombinant SSI was digested by trypsin using a ratio of 25:1 rSSI to trypsin, during an 18 hour incubation period. Approximately $15 \mu \mathrm{g}$ of rSSI peptides (A) was compared to a control of $1 \mu \mathrm{g}$ of fresh trypsin in solution (B) by performing SDS-PAGE and visualizing the proteins by silver staining. The Invitrogen protein standard ("Mark12") indicated that rSSI yielded peptides less than $20 \mathrm{kDa}$; in comparison, undigested rSSI is approximately $75 \mathrm{kDa}$. The trypsin added to the rSSI solution has also been digested.

\section{Scintillation Counting}

${ }^{32} \mathrm{P}$ radioactive decay was measured by an LS 6500 multipurpose liquid scintillation counter according to the manufacturer's instructions.

\section{Matrix-Assisted Laser Desorption/Ionization-Time of Flight}

Mass spectrometry was performed by the University of Guelph Mass Spectrometry facility using a Bruker MALDITOF as described by Mitchelhill and Kemp. ${ }^{8}$

\section{SSI Digestion by Trypsin}

Recombinant SSI was digested by sequencing grade modified trypsin using a procedure modified from the one provided by the manufacturer. Recombinant SSI attached to S-protein agarose was incubated at $95^{\circ} \mathrm{C}$ in $50 \mathrm{mM}$ Ammonium Bicarbonate and $20 \mathrm{mM}$ DTT with intermittent agitation for 7 minutes. After cooling, trypsin was added at a ratio of 1:50 and incubated with gentle rocking at $37^{\circ} \mathrm{C}$ for 2 hours. The same amount of trypsin was added again, and the solution was incubated for 16 hours at $37^{\circ} \mathrm{C}$ with gentle rocking. The peptides were collected in the supernatant after centrifugation at $13000 \mathrm{~g}$ for 2 minutes.

\section{Immobilized Metal Affinity Chromatography}

IMAC was performed using a HiTrap chelating HP column according to the manufacturer's instructions. The column was washed using $10 \mathrm{~mL}$ of water. Iron was bound to the column by loading $4 \mathrm{~mL}$ of $20 \mathrm{mM} \mathrm{Fe}(\mathrm{III}) \mathrm{Cl}_{3}$, and excess $\mathrm{Fe}^{3+}$ was washed away using $5 \mathrm{~mL}$ of water. The column was equilibrated with $3 \mathrm{~mL}$ of running buffer $(20 \mathrm{mM}$ sodium acetate $\mathrm{pH}$ 5.0) and the samples were subsequently loaded and allowed to bind to the column. Unbound peptides were then washed off using $10 \mathrm{~mL}$ of running buffer, and were eluted using $5 \mathrm{~mL}$ of $100 \mathrm{mM}$ sodium dihydrogen phosphate.

\section{Reversed-Phase High Pressure Liquid Chromatography}

Reversed-phase HPLC was performed using a Gemini-NX $3 \mu$ C18 110A column on an Agilent 1100 Series HPLC according to the manufacturer's instructions. The liquid phase was a gradient of HPLC grade water and acetonitrile, 


\section{Counts per Minute of 32-P Radioactive Decay Indicating the Presence of rSSI Phosphopeptides}

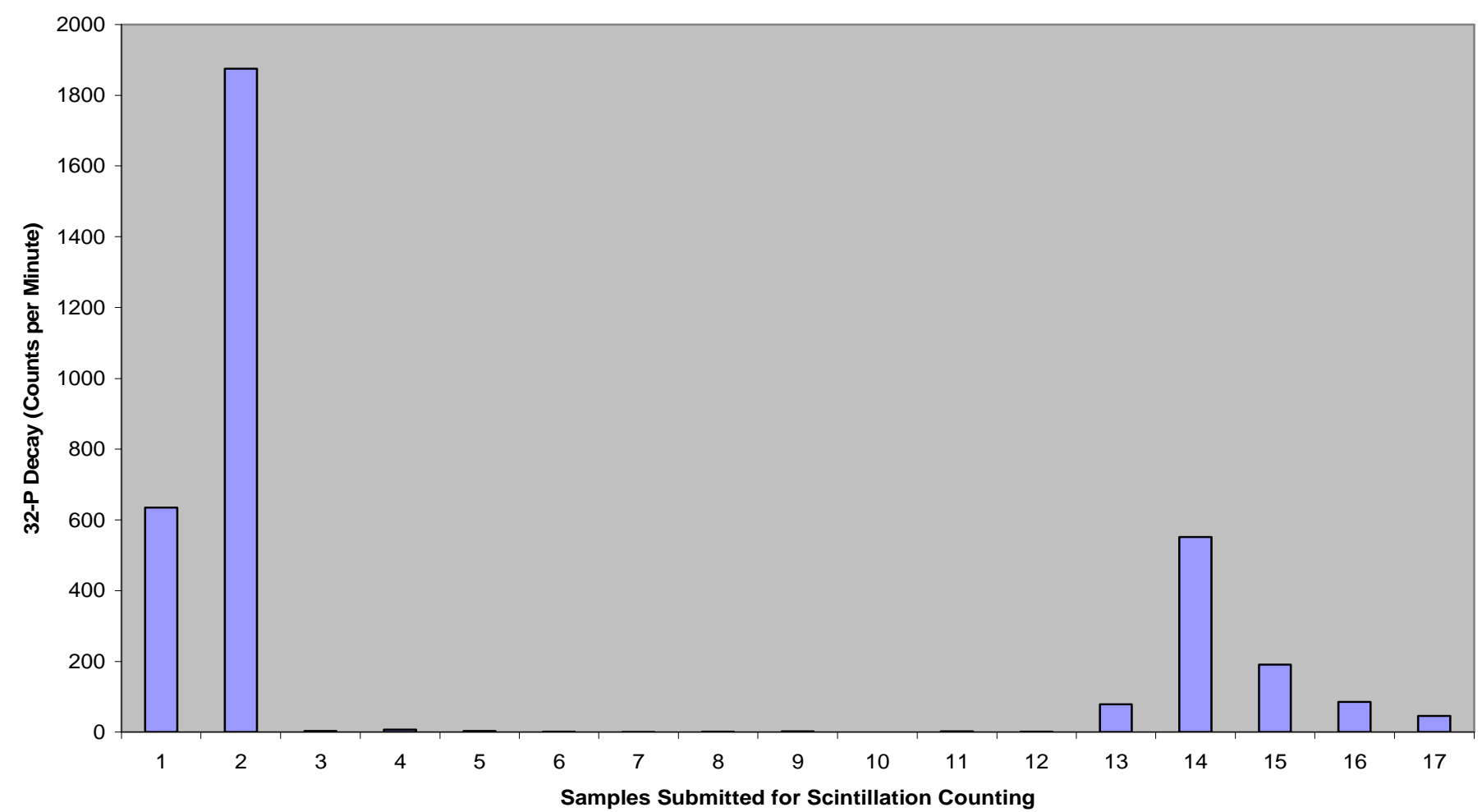

Figure 4: Scintillation counts of ${ }^{32} \mathrm{P}$ labeled rSSI phosphopeptides.

Recombinant SSI was phosphorylated in vitro by incubating it with $125 \mu \mathrm{Ci}$ of $\left[\gamma_{-}{ }^{32} \mathrm{P}\right]-\mathrm{ATP}$ and amyloplast lysates as a source of kinase. The sample was digested by incubating it with a ratio of 1:25 trypsin to rSSI for 18 hours. The sample was divided in two, and phosphopeptides were removed from the S-protein agarose. The amount of phosphopeptides that remained in the S-protein agarose was measured by scintillation counting, and is represented by sample 1 on the histogram. One portion of phosphopeptides extracted from S-protein agarose was loaded to the IMAC column, and the other was measured by scintillation counting to give the theoretical total loaded to the IMAC column (sample 2). The amount of phosphopeptides in each 1mL fraction of buffer eluted from the IMAC column was also measured by scintillation counting. Samples 3 through 12 are $1 \mathrm{~mL}$ fractions of running buffer, which was used to wash unwanted peptides from the column. Samples 13 through 17 are $1 \mathrm{~mL}$ fractions of elution buffer.

which was converted from $95 \%$ to $0 \%$ water over 38 minutes. Absorbance was detected for UV radiation at 217

\section{RESULTS}

Recombinant maize SSI was purified from Escherichia coli cells which had been transformed by plasmids containing the sequence for maize SSI. Peptide specific polyclonal maize SSI antibodies from rabbit antisera recognized and bound to the rSSI when immunoblotting was performed (data not shown). Activity was measured using a SSI zymogram, which showed that the recombinant protein was catalytically active (data not shown).
Recombinant maize SSI was phosphorylated when incubated with amyloplast lysates (as a source of kinase) and $\left[\gamma^{32} \mathrm{P}\right]$ ATP, and maximal phosphorylation was reached within 20 minutes. No significant changes in the level of phosphorylation occurred after 20 minutes as determined by densitometry (Figure 1). In all further experiments, rSSI was incubated with maize amyloplast lysates as a source of kinase for 20 minutes, followed by 30 minutes of incubation with protein S-protein Agarose, for a total of 50 minutes of incubation in the presence of ATP. Phosphoamino acid analysis of ${ }^{32} \mathrm{P}$ labelled rSSI was performed to determine which amino acid residue(s) were phosphorylated. The results indicated that rSSI is phosphorylated on one or more serine residues (Figure 2). Once this information had been 

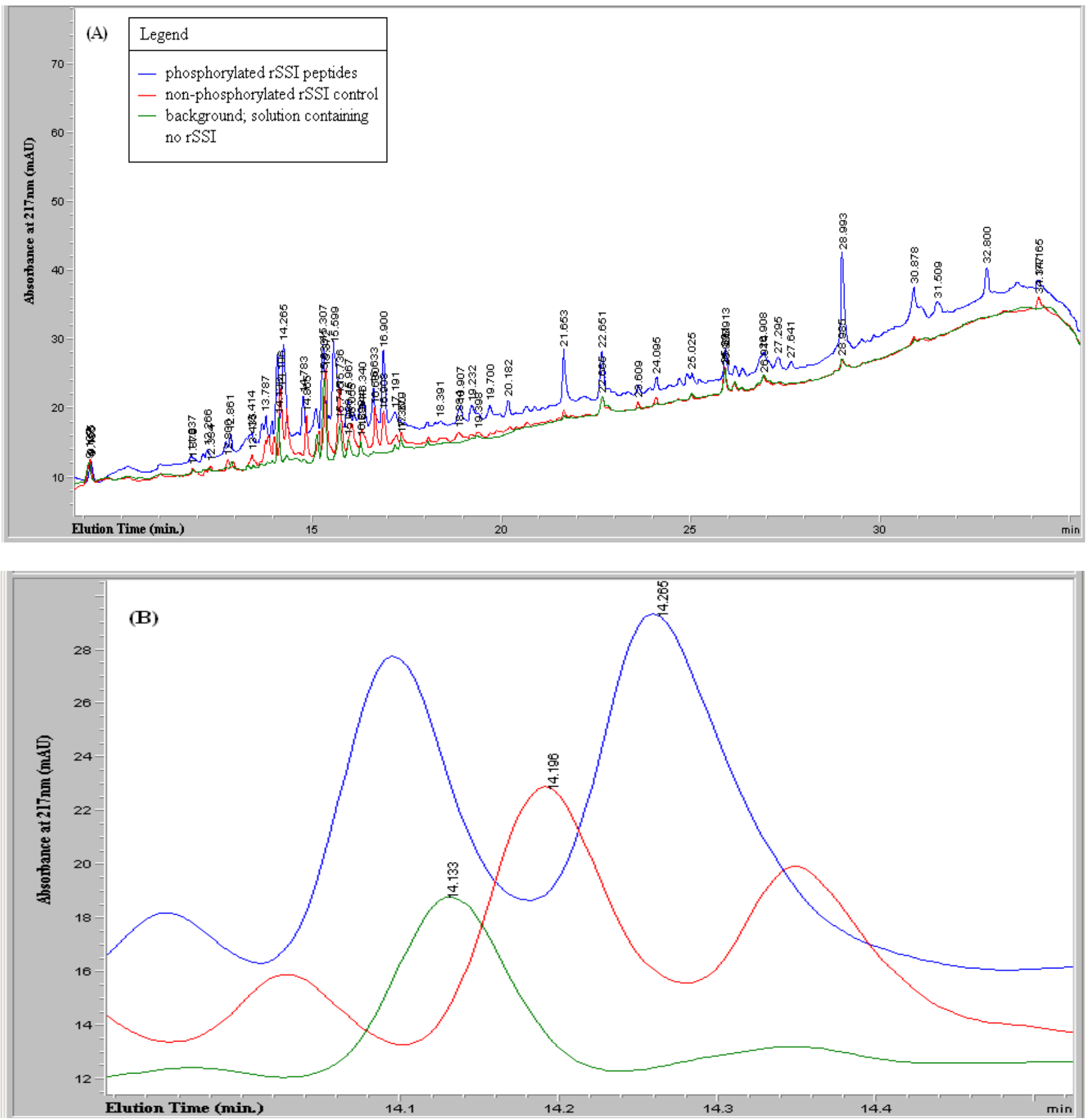

Figure 5: C-18 column reversed-phase HPLC absorbance at $217 \mathrm{~nm}$ for phosphorylated rSSI peptides, non-phosphorylated rSSI peptides and a background control lacking rSSI.

Figure 5A shows absorbance for molecules eluting from the C-18 HPLC column between 9 and 35 minutes. Figure 5B shows a close up of the absorbance values between 14 and 14.5 minutes. In both figures, the blue line represents a solution of trypsin digested, IMAC treated, phosphorylated rSSI. The red and green lines are controls: the red line represents a trypsin digested, IMAC treated, non-phosphorlated rSSI solution and the green line is a control identical to the other solution except without the addition of any rSSI. The blue absorbance peaks in this region do not correspond with either of the controls. Thus they could potentially have been created by phosphopeptides in the sample. 
Table 1: Theoretical monoisotopic masses for trypsin digested rSSI peptides. ${ }^{3}$

\begin{tabular}{|c|c|c|}
\hline Mass (Da) & Position & Peptide Sequence \\
\hline 7575.9310 & $9-85$ & EGPAPRPLPPALLAPPLVPGFLAPPAEPTGEPASTPPPVPDAGLGDLGLEPEGIAEGSIDNTVVVASEQDSEIVVGK \\
\hline 5391.5361 & $520-568$ & DTVENFNPFGENGEQGTGWA FAPLTTENMFVDIANCNIYI QGTQVLLGR \\
\hline 4945.4839 & $208-252$ & YTLLCYAACEAPLILELGGY IYGQNCMFVVNDWHASLVPV LLAAK \\
\hline 4658.3506 & $264-304$ & SILVIHNLAHQGVEPASTYP DLGLPPEWYGALEWVFPEWA R \\
\hline 2921.4436 & $493-519$ & FEPCGLNQLYAMQYGTVPVV HATGGLR \\
\hline 2703.2586 & 175-197 & DSVDWVFVDHPSYHRPGNLY GDK \\
\hline 2354.1258 & 333-354 & GYSWEVTTAEGGQGLNELLS SR \\
\hline 2353.0475 & 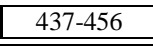 & EDVQFVMLGSGDPELEDWMR \\
\hline 2255.1302 & 356-376 & SVLNGIVNGIDINDWNPATD K \\
\hline 2067.9381 & $158-174$ & IPCFGGEHEVTFFHEYR \\
\hline 1962.1534 & 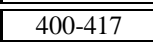 & $=$ ELGLPIRPDVPLIGFIGR \\
\hline 1796.9428 & $92-108$ & VTQSIVFVTGEASPYAK \\
\hline 1642.8581 & 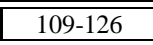 & SGGLGDVCGSLPVALAAR \\
\hline 1609.9345 & $423-436$ & GIDLIQLIIPDLMR \\
\hline 1536.6821 & $377-390$ & CIPCHYSVDDLSGK \\
\hline 1389.7228 & $\overline{4880-492}$ & ITAGCDILLMPSR \\
\hline 1327.6905 & $\overline{468-479}$ & GWVGFSVPVSHR \\
\hline 1220.5582 & $145-154$ & NYANAFYTEK \\
\hline 1158.5326 & $198-207$ & FGAFGDNQFR \\
\hline 1045.5465 & $253-260$ & YRPYGVYK \\
\hline 897.4312 & $\overline{137-144}$ & YLNGTSDK \\
\hline 877.4778 & 311-318 & GEAVNFLK \\
\hline 831.4579 & $130-136$ & VMVVMPR \\
\hline 811.4196 & 457-463 & STESIFK \\
\hline 788.4261 & $319-326$ & GAVVTADR \\
\hline 781.4137 & 578-584 & LHVGPCR \\
\hline$\overline{7777.3923}$ & $2-8$ & CVAELSR \\
\hline 666.3457 & 4 & LDYQK \\
\hline 646.4134 & 327-332 & IVTVSK \\
\hline 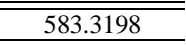 & 306-310 & HALDK \\
\hline$\overline{560.2787}$ & 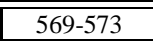 & ANEAR \\
\hline$\overline{516.3140}$ & 395-399 & GALQK \\
\hline 503.2572 & $86-89$ & EQAR \\
\hline 425.2619 & $155-157$ & HIR \\
\hline 383.2401 & 574-576 & $\overline{\mathrm{HVK}}$ \\
\hline 377.1779 & $261-263$ & $\overline{\mathrm{DSR}}$ \\
\hline 369.1993 & $127-129$ & $\overline{\overline{G H R}}$ \\
\hline 322.1873 & 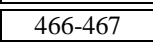 & $\overline{\overline{F R}}$ \\
\hline 262.1397 & $464-465$ & $\overline{\mathrm{DK}}$ \\
\hline 250.1220 & ב393-394 & $\overline{\overline{C K}}$ \\
\hline 218.1499 & $90-91$ & $\mathrm{AK}$ \\
\hline 218.1499 & 391-392 & $\overline{\mathrm{AK}}$ \\
\hline 175.1189 & $1-1$ & $\mathrm{R}$ \\
\hline 175.1189 & 305-305 & $\overline{\mathrm{R}}$ \\
\hline 175.1189 & 577-577 & $\overline{\bar{R}}$ \\
\hline 147.1128 & 355-355 & $\underline{\bar{K}}$ \\
\hline
\end{tabular}

The ExPasy PeptideMass specifications used were as follows: cysteines were untreated, thus they were reduced, and monoisotopic masses were returned such that zero missed cleavages was selected. For data analysis purposes, one missed cleavage was assumed (masses not shown). The input sequence of rSSI included amino acids 39 to 640, which corresponds to the mature maize SSI protein. ${ }^{6}$ A complete digestion of rSSI by trypsin should yield peptides with masses less than 8000 Da. A phosphate group has a mass of 79.9663 Da, thus a phosphopeptide should show a mass increase by a multiple of this amount. Source: ExPasy PeptideMass available from http://ca.expasy.org/tools/peptide-mass.html. 
Table 2: A comparison of masses returned by MALDI-TOF for fraction 15 eluted from the HPLC column and expected mass values for rSSI phosphopeptides.

\begin{tabular}{|c|c|}
\hline $\begin{array}{c}\text { Mass Identified by } \\
\text { MALDI-TOF } \mathbf{1 . 0} \text { Da }\end{array}$ & $\begin{array}{c}\text { Closest Expected rssI } \\
\text { Phosphopeptide Masses } \\
\text { (Da) }\end{array}$ \\
\hline 841.35 & 891.39 \\
\hline 1120.72 & 1134.51 \\
\hline 1177.91 & 1214.47 \\
\hline 1412.59 & 1407.66 \\
\hline 1518.43 & 1696.61 \\
\hline 1728.72 & 1722.82 \\
\hline 1881.51 & 1876.91 \\
\hline 2071.48 & 1956.88 \\
\hline 2102.95 & 2076.04 \\
\hline 2151.52 & 2076.04 \\
\hline 2166.25 & 2152.97 \\
\hline 2366.60 & 2156.01 \\
\hline 2484.04 & 2335.10 \\
\hline 3034.59 & 2463.19 \\
\hline 3064.71 & 3061.49 \\
\hline 3164.25 & 3061.49 \\
\hline 3206.26 & 3141.45 \\
\hline 3430.84 & 3225.42 \\
\hline 3487.66 & 3500.75 \\
\hline 6530.45 & 3500.75 \\
\hline & 4372.11 \\
\hline & 6164.97 \\
\hline
\end{tabular}

There are no matches with expected phosphopeptides of up to one missed cleavage within \pm 1.0 Da of the masses returned by MALDI-TOF. The closest match is 2151.52 to the expected mass of 2152.97; a double phosphorylation of a peptide containing amino acid residues 109 to 126 which results from one missed cleavage. This phosphopeptide is unlikely to be present in solution due to the discrepancy between the expected and actual mass.

obtained, the next step was to determine which specific serine residue(s) was/were phosphorylated. A method was developed in which phosphorylated rSSI was digested by trypsin; the phosphopeptides were enriched by IMAC; the enriched phosphopeptide were separated by reversed-phase HPLC; and potential phosphopeptides were analyzed by MALDI-TOF.

Digestion of rSSI by the protease trypsin yielded peptides (Figure 3). During this procedure, trypsin ultimately digested itself, implying that the solution contained a variety of peptides from both rSSI and trypsin. The masses of the resulting rSSI peptides were predicted using the Expasy PeptideMass online protein digestion tool published by the Swiss Institute of Bioinformatics (Table 1). ${ }^{3}$ A comparison of Figure 3 to the predicted masses of rSSI peptides (Table 1) indicates that the mass of the peptides was greater than predicted.

To obtain a solution enriched in phosphopeptides, IMAC was performed on the trypsin digested rSSI solution using a HiTrap chelating column. An experiment was conducted to ascertain the effectiveness of this procedure. The rSSI was labelled with ${ }^{32}-\mathrm{P}$, digested using trypsin, and scintillation counting was used to track the phosphopeptides (Figure 4). Approximately one third of the labelled phosphopeptides could not be loaded to the IMAC column because they remained in the S-protein agarose pellet. The peptides solubilised from the S-protein agarose did bind to the IMAC column matrix, and only half were eluted from the column in the elution buffer. The rest remained bound to the column. HPLC was performed on trypsin digested rSSI samples. Putative phosphopeptides were identified by the presence of an absorbance peak for the phosphorylated sample, but not in samples that lacked the ATP treatment, which were used as a control (Figure 5). Analysis by MALDI-TOF was performed, but no expected phosphopeptide masses were returned (Table 2).

\section{DISCUSSION}

The rSSI phosphorylation time course experiment was performed to ensure that maximum phosphorylation could be achieved before further analyses were performed. Maximal phosphorylation was reached within 20 minutes and remained stable thereafter, which was information used when designing subsequent experiments. These experiments highlighted the importance of ensuring that non-specific binding of amyloplast proteins to S-protein agarose did not occur. Two-hundred and fifty [250] $\mathrm{mL}$ of a harsh wash buffer containing DTT, Triton X-100 and $750 \mathrm{mM} \mathrm{NaCl}$ were used to strip away all other proteins from the affinity resin. Additionally, the S-protein agarose was blocked with $1.5 \%$ bovine serum albumin prior to adding it to rSSI at a ratio of $1: 1$ by mass to reduce non-specific binding of proteins to $\mathrm{S}$ protein agarose as has been used previously.

Phosphoamino acid analysis indicated that one or more serine residues on rSSI were phosphorylated, contrary to threonine or tyrosine, which were not. The rSSI contained SSI amino acid residues 39 to 640 which represent the mature protein. ${ }^{6}$ Between residue 39 and 640 there are 28 serine residues, any of which could be the target of the plastidial protein kinase(s). Further experiments were developed to ascertain which specific serine residue(s) represented the phosphorylation site(s) of rSSI.

Further optimization of rSSI trypsin digestion may be necessary, as results indicated that rSSI was not completely digested. However, the scintillation counts of ${ }^{32}$-P-labelled phosphopeptides indicates that there was phosphopeptide recovery from the IMAC column. Subsequent separation by reversed-phase HPLC and analysis by MALDI-TOF yielded no masses corresponding to the predicted values for rSSI phosphopeptides within $\pm 1 \mathrm{Da}$. This may have occured because the isolated phosphopeptide(s) were outside the optimal range for detection by MALDI-TOF (between 800Da and $2500 \mathrm{Da}$ ). Optimization of the trypsin digestion procedure may reduce peptide masses to within the optimal range, or conversely, digestion by another protease could 
produce phosphopeptides of more amenable sizes. Alternatively, analysis of the phosphopeptides by reversedphase HPLC could have been compromised because the concentration was insufficient for detection. The scintillation counts of ${ }^{32} \mathrm{P}$-labelled peptides indicated that approximately one third remained in the S-protein agarose pellet and approximately half of the amount loaded to the IMAC column did not elute. As a result, the concentration of phosphopeptides in the solution was very low, and phosphopeptides may not have been detectable as they eluted from the C-18 HPLC column. In future experiments, optimizing the IMAC procedure may help to increase the recovery of phosphopeptides, or adequate concentrations can be ensured by pooling IMAC eluate and concentrating it.

Recombinant SSI was used for these experiments due to the ease of manipulating significant amounts of this protein for downstream protein chemistry applications. However, the use of recombinant proteins has some drawbacks. For example, the rSSI used contained an S-tag fused to the Nterminus of the enzyme, which could affect its 3D conformation and interaction with other proteins such as kinases. Another drawback of using rSSI is that during the purification and refolding procedure, it is likely that not all of the rSSI refolded into the same conformation as native SSI. This could affect the protein's interaction with kinases and thus the degree to which the protein might be phosphorylated in vitro. Ideally, additional experiments should be conducted with native maize SSI to confirm that any phosphorylation sites found on the recombinant protein are indeed phosphorylated in vivo.

In summary, we have shown that in vitro phosphorylation of recombinant maize SSI can occur at one or more serine residues through the action of an endogenous plastidial protein kinase. In spite of the fact that no phosphopeptides have been characterized, these experiments indicate that the specific identification of rSSI phosphorylation sites via this method is feasible. Further experiments designed to optimize the IMAC procedure, and the use of additional or alternative proteases, might overcome encountered technical problems.

\section{ACKNOWLEDGEMENTS}

This research could not have been performed without the aid and supervision of Dr. Nadya Romanova, Professor Ian J. Tetlow (faculty supervisor) and Michael J. Emes, who also contributed significantly to this work. Funding for this research was in part provided by the Natural Sciences and Engineering Research Council (NSERC) of Canada through the Undergraduate Student Research Award (USRA) program. Finally, we would like to thank Professor John Greenwood who kindly agreed to review this article.

\section{REFERENCES}

1. Ball, S. G., and Morrell, M. K. 2003. From Bacterial Glycogen to Starch: Understanding the Biogenesis of the Plant Starch Granule. Annual Review Plant Biology, 54: 207-233.

2. Commuri, P. D., and Keeling, P. L. 2001. Chain-length specificities of maize starch synthase I enzyme: studies of glucan afinity and catalytic properties. The Plant Journal, 25: 475-486.

3. Gasteiger E., Gattiker A., Hoogland C., Ivanyi I., Appel R.D. and Bairoch A. 2003. ExPASy: the proteomics server for in-depth protein knowledge and analysis. Nucleic Acids Res, 31: 3784-3788.

4. Harlow, E. and Lane, D. 1999. Antibodies: A Laboratory Manual. Cold Spring Harbor (NY): Cold Spring Harbor Laboratory Press.

5. Hennen-Bierwagen, T. A., Liu, F., Marsh, R. S., Kim, S., Gan, Q., Tetlow, I. J., Emes, M. J., James, M. G., and Myers, A. M. 2008. Starch Biosynthetic Enzymes from Developing Maize Endosperm Associate in Multisubunit Complexes. Plant Physiology, 146: 1892-1908.

6. Knight, M. E., Harn, C., Lilley, C. E. R., Guan, H., Singletary, G., W., Mu-Forster, C., Wasserman, B. P., and Keeling P. L. 1998. Molecular cloning of starch synthase I from maize (W64) endosperm and expression in Escherichia coli. The Plant Journal, 14: 613-622.

7. Liu, F., Makhmoudova, A., Lee, E. A., Wait, R., Emes, M. J., and Tetlow, I. J. 2009. The Amylose Extender Mutant of Maize Conditions Novel Protein-Protein Interactions between Starch Biosynthetic Enzymes in Amyloplasts. Journal of Experimental Botany. In Press.

8. Mitchelhill, K. I. and Kemp, B. E. 1999. Phosphorylation site analysis by mass spectrometry. D. G. Hardie, ed. In Protein Phosphorylation a Practical

Approach. $2^{\text {nd }}$ ed. New York (NY): Oxford University Press. p 127-151.

9. Myers, A. M., Morrell, M. K., James, M. G., and Ball, S. G. 2000. Recent Progress toward Understanding Biosynthesis of the Amylopectin Crystal. Plant Physiology, 122: 989-997.

10. Nakamura, Y., Kubo, A., Shimamune, T., Matsuda, T., Harada, K., and Satoh, H. 1997. Correlation between activities of starch debranching enzyme and $\alpha$ polyglucan structure in endosperms of sugary-1 mutants of rice. The Plant Journal, 12: 143-153.

11. Shevchenko, A., Wilm, M., Vorm, O., and Mann, M. 1996. Mass Spectrometric Sequencing of Proteins from Silver-Stained Polyacrylamide Gels. Analytical Chemistry, 68: 850-858. 
12. Szydlowski, N., Ragel, P., Raynaud, S., Lucas, M. M., Roldán, I., Montero, M., Muñoz, F. J., Ovecka, M., Bahaji, A., Planchot, V., Pozueta-Romero, J., D'Hulst, C., and Mérida, A. 2009. Starch Granule Initiation in Arabidopsis Requires the Presence of Either Class IV or Class III Starch Synthases. The Plant Cell Advance Online Publication, tpc.109.066522v1.

13. Tetlow, I. J., Beisel, K. G., Cameron, S., Makhmoudova, A., Liu, F., Bresolin, N. S., Wait, R., Morell, M. K., and Emes, M. J. 2008. Analysis of Protein Complexes in Wheat Amyloplasts Reveals Functional Interactions among Starch Biosynthetic Enzymes. Plant Physiology, 146: 1878-1891.

14. Tetlow, I. J. 2006. Understanding storage starch biosynthesis in plants: a means to quality improvement. Canadian Journal of Botany, 84: 1167-1185.

15. Tetlow, I.J., Morell, M.K., and Emes, M.J. 2004a. Recent Developments in understanding the Regulation of Starch Metabolism in Higher Plants. Journal of Experimental Botany, 55: 2131-2145.

16. Tetlow, I. J., Wait, R., Lu, Z., Akkasaeng, R., Bowsher, C. G., Esposito, S., Kosar-Hashemi, B., Morell, M., and Emes, M. J. 2004b. Protein Phosphorylation in Amyloplasts Regulates Starch Branching Enzyme Activity and Protein-Protein Interactions. The Plant Cell, 16: 694-708.

17. Turkina, M. V., and Vener, A. V. 2007. Identification of Phosphorylated Proteins. H. Thiellement, M. Zivy, C. Damerval, and V. Mechin, eds. In Plant Proteomics Methods and Protocols. Totowa (NJ): Human Press Inc. p. 305-316.

18. Van der Greer, P., Luo, K., Sefton, B. M. and Hunter, T. 1999. Phosphopeptide mapping and phosphoamino acid analysis on cellulose thin-layer plates. D. G. Hardie, ed. In Protein Phosphorylation a Practical Approach. $2^{\text {nd }}$ ed. New York (NY): Oxford University Press. p 97-126. 